\title{
The association between endotoxin and lung function among children and adolescents living in a rural area
}

\author{
Joshua A Lawson $\mathrm{PhD}^{1}$, James A Dosman SOM MD${ }^{1}$, Donna C Rennie $\mathrm{PhD}^{1}$, Jeremy Beach $\mathrm{MD}^{4}$, \\ Stephen C Newman MD5 , Ambikaipakan Senthilselvan $\mathrm{PhD}^{6}$
}

JA Lawson, JA Dosman, DC Rennie, J Beach, SC Newman, A Senthilselvan. The association between endotoxin and lung function among children and adolescents living in a rural area. Can Respir J 2011;18(6):e89-e94.

BACKGROUND/OBJECTIVES: Knowledge of the effects of domestic endotoxin on children's lung function is limited. The association between domestic endotoxin and asthma or wheeze and lung function among school-age children (six to 18 years of age) was examined. The interaction between endotoxin and other personal and environmental characteristics and lung function was also assessed.

METHODS: A case-control study was conducted in and around the rural community of Humboldt, Saskatchewan, between 2005 and 2007. Parents of cases reported either doctor-diagnosed asthma or wheeze in the previous year. Controls were randomly selected from those not reporting these conditions. Data were collected by questionnaire to ascertain symptoms and conditions, while spirometry was used to measure lung function including forced vital capacity and forced expiratory volume in $1 \mathrm{~s}$. Dust collected from the child's play area floor and the child's mattress was used to quantify endotoxin, and saliva was collected to quantify cotinine levels and assess tobacco smoke exposure.

RESULTS: There were 102 cases and 207 controls included in the present study. Lower forced expiratory volume in $1 \mathrm{~s}$ was associated with higher mattress endotoxin load among female cases (beta $=-0.25$, $\mathrm{SE}=0.07[\mathrm{P}<0.01])$. There was a trend toward lower forced vital capacity, which was associated with higher play area endotoxin load among cases with high tobacco smoke exposure (beta $=-0.17, \mathrm{SE}=0.09[\mathrm{P}<0.10]$ ).

CONCLUSIONS: Findings indicated that high endotoxin levels present in common household areas of rural children with asthma or wheeze may also affect their lung function. These associations may be potentiated by tobacco smoke exposure and female sex.

Key Words: Asthma; Endotoxin; Lung function; Rural; Tobacco smoke; Wheeze

A thma is a chronic respiratory disease that can lead to activity limitation, school absenteeism and hospitalization. It accounts for a large proportion of health care resource use, especially among children. The environment is known to play an important role in both the development of asthma and in subsequent disease exacerbations. Endotoxin is an exposure of which levels have been reported to be higher in rural and agricultural areas $(1,2)$. It is believed that endotoxin exhibits a paradoxical proinflammatory effect on respiratory health and, therefore, has the ability to exacerbate asthma (3), but could also modify the immune response and potentially protect against the development of atopic disease (4). While the role of household endotoxin has been studied in relation to the presence of asthma - with inconsistent results (5-8) - few studies outside of occupational settings have considered the associations between lung function and endotoxin exposure. In a small study involving children (9) and two clinic-based

\section{L'association entre les endotoxines et la fonction pulmonaire chez les enfants et les adolescents qui habitent en région rurale}

HISTORIQUE ET OBJECTIFS : On connaît peu les effets de l'exposition domestique aux endotoxines sur la fonction pulmonaire des enfants. Les chercheurs ont examiné l'association entre l'exposition domestique aux endotoxines et l'asthme ou la respiration sifflante et la fonction pulmonaire chez les enfants d'âge scolaire (de six à 18 ans). Ils ont également évalué l'interaction entre les endotoxines et les autres caractéristiques personnelles et environnementales et la fonction pulmonaire.

MÉTHODOLOGIE : Les auteurs ont mené une étude cas-témoin dans la collectivité et les environs de Humboldt, en Saskatchewan, entre 2005 et 2007. Les parents des cas ont signalé soit un asthme diagnostiqué par le médecin, soit une respiration sifflante au cours de l'année précédente. Les sujets témoins ont été sélectionnés au hasard à partir de personnes qui n'avaient pas signalé ces problèmes. Les chercheurs ont colligé les données par questionnaire pour évaluer les symptômes et les problèmes et utilisé la spirométrie pour mesurer la fonction pulmonaire, y compris la capacité vitale forcée et le volume expiratoire forcé par seconde. Ils ont recueilli la poussière sur le plancher de l'aire de jeux et sur le matelas de l'enfant pour quantifier les endotoxines, ainsi que la salive pour quantifier les taux de cotinine et évaluer l'exposition à la fumée secondaire.

RÉSULTATS : Cent deux (102) cas et 207 sujets témoins étaient inclus dans la présente étude. Le volume expiratoire inférieur par seconde s'associait à une charge d'endotoxines plus élevée dans le matelas des sujets de sexe féminin (bêta $=-0,25$, ÉT $=0,07[\mathrm{P}<0,01]$ ). On constatait une tendance vers une capacité vitale expiratoire inférieure qui s'associait à une charge d'endotoxines plus élevée dans l'aire de jeux chez les cas qui étaient fortement exposés à la fumée secondaire (bêta $=-0,17$, ÉT $=0,09[\mathrm{P}<0,10]$ ). CONCLUSIONS : Les observations indiquent que de forts taux d'endotoxines présents dans des secteurs communs de la maison d'enfants de régions rurales atteints d'asthme ou de respiration sifflante peuvent nuire à leur fonction pulmonaire. Ces associations peuvent être potentialisées par l'exposition à la fumée secondaire et le sexe féminin.

studies involving adults $(10,11)$, lower lung function was associated with higher endotoxin levels.

Environmental tobacco smoke (ETS) has been shown to negatively impact lung function in children (12). There are several reasons why ETS should be considered along with endotoxin as a potential effect modifier including the following: ETS is associated with higher endotoxin levels $(8,13)$; ETS includes other proinflammatory agents in addition to endotoxin; and it has the potential to modify associations between occupations high in endotoxin exposure and respiratory outcomes (14). The interactions between ETS exposure and household endotoxin in children have not been reported. We examined associations between household endotoxin exposure and lung function in children living in a rural region, and examined the modifying effects of sex, pre-existing asthma and other environmental exposures, including ETS, in this association.

${ }^{1}$ Canadian Centre for Health and Safety in Agriculture, ${ }^{2}$ Department of Medicine, ${ }^{3}$ College of Nursing, University of Saskatchewan, Saskatoon,

Saskatchewan; ${ }^{4}$ Department of Medicine; ${ }^{5}$ Department of Psychiatry, Faculty of Medicine and Dentistry; ${ }^{6}$ Department of Public Health

Sciences, School of Public Health Sciences, University of Alberta, Edmonton, Alberta

Corrspondence: Dr Joshua A Lawson, 3641-103 Hospital Drive, Canadian Centre for Health and Safety in Agriculture, Royal University

Hospital, University of Saskatchewan, Saskatoon, Saskatchewan S7N OW8. Telephone 306-966-2978, fax 306-966-8799,

e-mail josh.lawson@usask.ca. 


\section{METHODS}

\section{Study design and population}

A case-control study of children dwelling in and around the rural community of Humboldt, Saskatchewan, a primarily agriculture-based community, during the spring, fall and winter seasons (March 2005 to April 2007) was conducted. Subjects were recruited from a 2004 crosssectional study of children six to 18 years of age. Potential cases were included if they reported doctor-diagnosed asthma, or if they reported wheeze in the previous 12 months. Potential controls were selected randomly from those who did not report asthma or wheeze, and who participated in the cross-sectional study. An attempt was made to recruit two controls for each case. Once selected, an invitation letter was mailed and followed up by telephone calls. On contact, a screening questionnaire was administered, and subjects were confirmed as cases or controls. To increase participation, the study area was extended to include rural communities and farming areas around Humboldt and in the same school district as Humboldt. Selection and recruitment followed an identical process. Data collection methods included questionnaires, lung function testing, dust collection for endotoxin and saliva collection for cotinine. The Health Research Ethics Board - Panel A (University of Alberta [Edmonton, Alberta]) and the Biomedical Research Ethics Board (University of Saskatchewan [Saskatoon, Saskatchewan]) approved the study, as did the local school boards. Before participating, parents and children completed consent and assent forms, respectively.

\section{Questionnaires}

Questionnaires based on standardized questionnaires (15-17) and questionnaires from previous studies conducted in Humboldt (18) and Estevan $(8,19)$, Saskatchewan, were administered by an interviewer to a parent of the subject. Information regarding sociodemographic factors, respiratory health, general health, parental health history, birth characteristics, lifestyle (eg, diet, physical activity and smoking), housing characteristics (eg, age of home, number of rooms/occupants, type of heating, presence of air conditioning, humidifiers or air filters), and environmental exposures (eg, ETS, mould or pets) was collected. Season of testing was defined based on the date of the home visit and was recorded as spring (March, April or May), fall (September, October or November) or winter (December, January or February).

\section{Collection and analysis of dust samples to quantify endotoxin exposure}

Two samples of settled household dust were collected from the homes. These included the room in which the child spent most of their free time (play area), and from the child's bed (mattress). The dust was collected by one of two identical vacuum cleaners (Solaris Miele S514, Germany) and was collected following International Study of Asthma and Allergies in Childhood (ISAAC) protocol (20) for time and size of area of vacuuming, but used a sock filter made of Connaught satin with a pore size of approximately $5 \mu \mathrm{m}$ to $10 \mu \mathrm{m}$ (21). Temperature and humidity were measured at the time of vacuuming.

Endotoxin levels in the house dust were quantified following the protocol of Gerada et al (22). Laboratory technicians were blinded to the case-control status of the subjects and to all other data collected. Quantitative assays to determine the levels of endotoxin were completed using the kinetic chromogenic Limulus assay (Cambrex Bio Science, Kinetic QCL, USA). Endotoxin levels were expressed as concentration (endotoxin units [EU] per mg of dust collected [EU/mg]) and load $\left(\mathrm{EU} / \mathrm{m}^{2}\right.$ of area vacuumed). Endotoxin measures were logtransformed before statistical analysis.

Collection and analysis of saliva samples to quantify cotinine levels Tobacco smoke exposure was determined by measuring salivary cotinine levels. Children were asked to spit into a specimen container without the use of materials that would stimulate the flow of saliva including gum or Teflon. Up to $5 \mathrm{~mL}$ of saliva were collected from each subject. Cotinine was quantified using cotinine microplate enzyme immunoassay kits (Cozart plc, United Kingdom). Because the distribution of salivary cotinine levels $(\mathrm{ng} / \mathrm{mL})$ were highly skewed and did not normalize after log transformation, cotinine levels were categorized at the median cotinine level $(1.24 \mathrm{ng} / \mathrm{mL})$. This cut-off is reflective of the lower end of mean $(1.31 \mathrm{ng} / \mathrm{mL})$ and median $(1.0 \mathrm{ng} / \mathrm{mL})$ cotinine values of passively exposed children from a previous population-based study (23).

\section{Lung function testing}

Lung function was assessed adhering to American Thoracic Society guidelines (24) with a dry-rolling seal spirometer (Sensormedics model 922; Sensormedics Corporation, USA). Children completed the testing in a sitting position while wearing a nose clip. At least three, and no more than seven, manoeuvres were attempted. Height and weight were measured objectively. Temperature $\left({ }^{\circ} \mathrm{C}\right)$, barometric pressure $(\mathrm{mmHg})$, and relative humidity (\%) (Traceable Model No. 61161 396, Friendswood, USA) were collected at the time of testing. Lung function outcomes included forced vital capacity (FVC) and forced expiratory volume in $1 \mathrm{~s}\left(\mathrm{FEV}_{1}\right)$. Per cent predicted values for lung function were determined based on predicted equations for children (25).

\section{Statistical analysis}

Analysis was completed using STATA version 9.0 (StataCorp LP, USA). The two outcomes of interest in the present analysis were FVC and $\mathrm{FEV}_{1}$. Comparisons of lung function levels were made between cases and controls based on absolute values using analysis of covariance to adjust for age, sex and height. During the descriptive analysis, levels of endotoxin were categorized at the median to define high and low. For play area endotoxin load, this was $1011.3 \mathrm{EU} / \mathrm{m}^{2}$, and for mattress endotoxin load, this was $402.5 \mathrm{EU} / \mathrm{m}^{2}$.

A multiple regression model was fitted for each log-transformed continuous measure of endotoxin that was independent of the other models: model 1 assessed play area endotoxin concentration; model 2 assessed play area endotoxin load; model 3 assessed mattress endotoxin concentration; and model 4 assessed mattress endotoxin load. Throughout the analyses, generalized estimating equations with an exchangeable working correlation were used to account for clustering within families. If the model did not converge, an independent working correlation was used. In addition to one of the four measures of endotoxin, each model included the following covariates: tobacco smoke exposure, age group, sex, height, season of testing and casecontrol status.

We considered several three-way and two-way interaction terms to be of clinical importance. Variables that were considered in this interaction analysis, which were identified a priori, included case-control status, a measure of endotoxin, tobacco smoke exposure and sex. Casecontrol status was included in this assessment to assess whether associations were consistent between those with and without asthma or wheeze, because most population-based studies investigating endotoxin and lung function have been completed only among children or adults with asthma (9-11), or have been completed in laboratory studies and showed larger responses in persons with asthma (26). Endotoxin and tobacco smoke exposures were included in this assessment because these were the independent variables of primary interest. Finally, sex was included because several studies have shown differential effects of environmental exposures between males and females on lung health (27-30). The following three-way interaction terms were tested: case-control status*sex*endotoxin, case-control status*sex*tobacco smoke exposure, case-control status*tobacco smoke exposure*endotoxin. In the event that the three-way interaction terms were not statistically significant, two-way interactions including these variables were assessed.

\section{RESULTS}

Among cases and controls in which contact had been made and who were eligible, $322(43.4 \%)$ children and their parents agreed to participate in the study. Of these, 12 subjects did not have either dust or 
TABLE 1

Distribution of age, anthropometric and lung function values among cases and controls

\begin{tabular}{|c|c|c|c|}
\hline & Controls $(n=207)$ & Cases $(n=102)$ & $\mathbf{P}$ \\
\hline Age, years & $11.5(11.1-12.0)$ & $11.3(10.7-11.9)$ & 0.50 \\
\hline Height, cm & $152.3(150.0-154.6)$ & 151.3 (147.9-154.7) & 0.55 \\
\hline Weight, kg & $49.4(46.8-52.0)$ & $49.4(45.7-53.1)$ & 0.92 \\
\hline \multicolumn{4}{|l|}{$\mathrm{FEV}_{1}$} \\
\hline$L^{*}$ & 2.79 (2.67-2.93) & $2.82(2.63-3.02)$ & 0.26 \\
\hline$\%$ predicted & $108.1(106.5-109.6)$ & $109.2(106.7-111.7)$ & 0.44 \\
\hline \multicolumn{4}{|l|}{ FVC } \\
\hline$L^{*}$ & 3.25 (3.09-3.41) & 3.39 (3.15-3.63) & 0.02 \\
\hline$\%$ predicted & $109.0(107.5-110.5)$ & 113.8 (111.5-116.0) & $<0.01$ \\
\hline \multicolumn{4}{|l|}{ FEF $_{25-75}$} \\
\hline $\mathrm{L} / \mathrm{S}^{*}$ & 3.22 (3.07-3.38) & $3.04(2.81-3.26)$ & 0.21 \\
\hline$\%$ predicted & $106.4(103.1-109.7)$ & 100.6 (95.6-105.5) & 0.05 \\
\hline \multicolumn{4}{|l|}{$\mathrm{FEV}_{1} / \mathrm{FVC}$ ratio } \\
\hline Ratio percentage* & $86.6(85.8-87.4)$ & $83.8(82.6-85.0)$ & $<0.001$ \\
\hline$\%$ predicted & $97.3(96.4-98.2)$ & 94.1 (92.7-94.5) & $<0.001$ \\
\hline
\end{tabular}

Data presented as mean $\left(95 \% \mathrm{Cl}\right.$ ) unless otherwise indicated. ${ }^{*}$ Crude values are presented, although statistical comparisons between the absolute values for cases and controls are based on the multiple linear regression adjusting for age group, sex and height and using generalized estimating equations to account for clustering within families. FEF $25-75$ Forced expiratory flow between

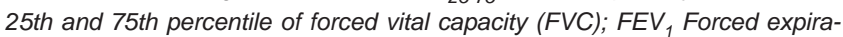
tory volume in $1 \mathrm{~s} ; F_{1} V_{1} / F V C F E V_{1}$ as a proportion of FVC expressed as a percentage

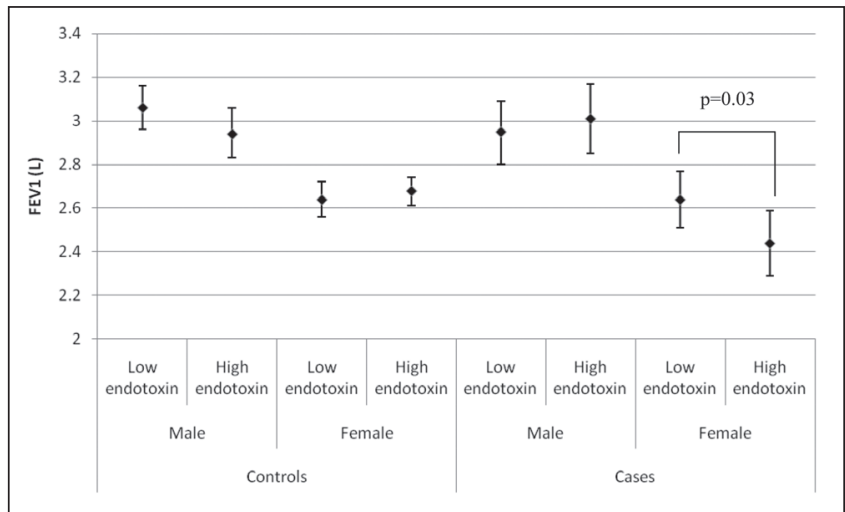

Figure 1) Adjusted (for age, height and mattress endotoxin load) forced expiratory volume in $1 \mathrm{~s}\left(\mathrm{FEV}_{1}\right)$ according to case-control status, sex and mattress endotoxin load $\left(E U / m^{2}\right)$

cotinine samples, and one subject refused lung function testing, leaving 102 cases and 207 controls for the present analysis. As shown in Table 1, there were no statistically significant differences between cases and controls with regard to age, height or weight, but there was a higher proportion $(\mathrm{P}<0.01)$ of males among cases $(64.7 \%)$ than among controls (39.6\%). Mean adjusted FVC was significantly higher among cases compared with controls (Table 1). In addition, per cent predicted forced expiratory flow in the $25 \%$ to $75 \%$ of FVC and $\mathrm{FEV}_{1} / \mathrm{FVC}$ ratio were significantly lower among cases than among the controls (Table 1).

As shown in Figure 1, $\mathrm{FEV}_{1}$ values were similar when comparing groups with high and low endotoxin exposure among male cases and controls, and female controls; however, the same was not true for female cases. Among female cases, the mean $\mathrm{FEV}_{1}$ was lower when higher endotoxin levels were present compared with those with lower endotoxin levels. FVC levels were similar, regardless of endotoxin levels for controls. Among cases with low tobacco smoke exposure, a higher endotoxin exposure was associated with a higher FVC (Figure 2).

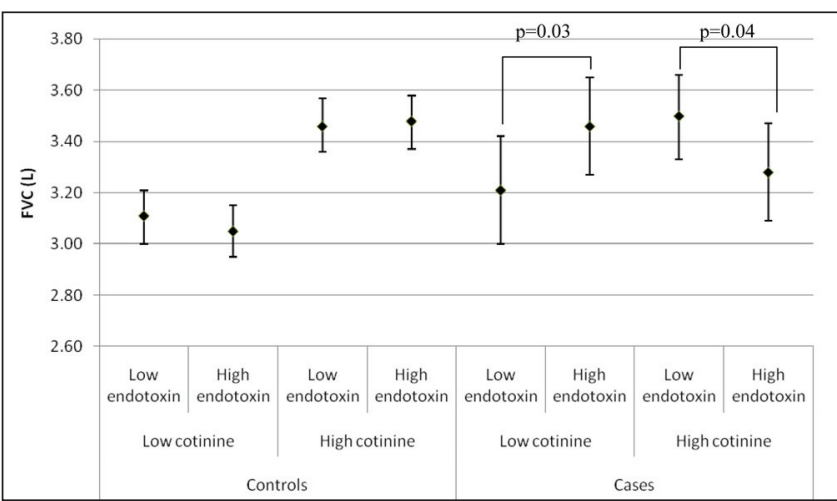

Figure 2) Adjusted (for age, sex, height, and play area endotoxin load) forced vital capacity (FVC) according to case-control status, tobacco smoke exposure and play area endotoxin load $\left(\mathrm{EU} / \mathrm{m}^{2}\right)$

TABLE 2

Adjusted multiple regression models* examining the association between endotoxin and lung function

\begin{tabular}{|c|c|c|}
\hline & \multicolumn{2}{|c|}{ Beta (SE) } \\
\hline & $\mathrm{FEV}_{1}(n=309)$ & FVC $(n=309)$ \\
\hline Model 1: Log play area endotoxin, EU/mg & $-0.002(0.04)$ & $0.05(0.04)$ \\
\hline Model 2: Log play area endotoxin, EU/m² & $-0.02(0.04)$ & $\dagger$ \\
\hline Control Low tobacco & & $0.03(0.05)$ \\
\hline Control High tobacco & & $-0.0007(0.06)$ \\
\hline Low tobacco & & $0.17(0.12)$ \\
\hline High tobacco & & $-0.17(0.09)^{\ddagger}$ \\
\hline Model 3: Log mattress endotoxin, EU/mg & $-0.03(0.04)$ & $-0.03(0.05)$ \\
\hline Model 4: Log mattress endotoxin, EU/m² & $\S$ & $-0.04(0.04)$ \\
\hline Control Male & $-0.04(0.07)$ & \\
\hline Female & $0.03(0.06)$ & \\
\hline Case & $0.09(0.07)$ & \\
\hline Female & $-0.25(0.07)^{\uparrow}$ & \\
\hline
\end{tabular}

*Adjustment for each variable listed for that model as well as age group, sex, case-control status, height, season of testing, tobacco smoke exposure and one measure of endotoxin; ${ }^{\dagger}$ Additionally adjusted for case-control status*tobacco smoke exposure, case-control status*play area endotoxin load, play area endotoxin load*tobacco smoke exposure and case-control status*tobacco smoke exposure*play area endotoxin load; ${ }^{\ddagger} P<0.10$; ${ }^{\S}$ Additionally adjusted for case-control status*sex, case-control status*mattress endotoxin load, mattress endotoxin load*sex and case-control status*sex ${ }^{\star}$ mattress endotoxin load; ${ }^{\top} P<0.01$. EU Endotoxin units; FEV 1 Forced expiratory volume in $1 \mathrm{~s}$; FVC Forced vital capacity

In contrast, among cases with high tobacco smoke exposure, a higher endotoxin exposure was associated with a lower FVC (Figure 2).

There was a statistically significant $(\mathrm{P}=0.003)$ three-way interaction between case-control status, mattress endotoxin load and sex when $\mathrm{FEV}_{1}$ was considered. Among controls, the association between mattress endotoxin load and $\mathrm{FEV}_{1}$ was similar for males and females (Table 2, Figure 3). However, among female cases only, lower FEV was associated with higher mattress endotoxin load (Table 2, Figure 3). With regard to $\mathrm{FEV}_{1}$, there was no statistically significant interaction between endotoxin and tobacco smoke exposure.

There was a three-way interaction of borderline statistical significance $(\mathrm{P}=0.07)$ between case-control status, play area endotoxin load and tobacco smoke exposure when considering FVC. Cases with high tobacco smoke exposure and higher levels of play area endotoxin load also had lower FVC ( $\mathrm{P}<0.10$; Table 2, Figure 4). Among controls, the association between play area endotoxin load and FVC was similar between those with high or low tobacco smoke exposure (Table 2, Figure 4). 

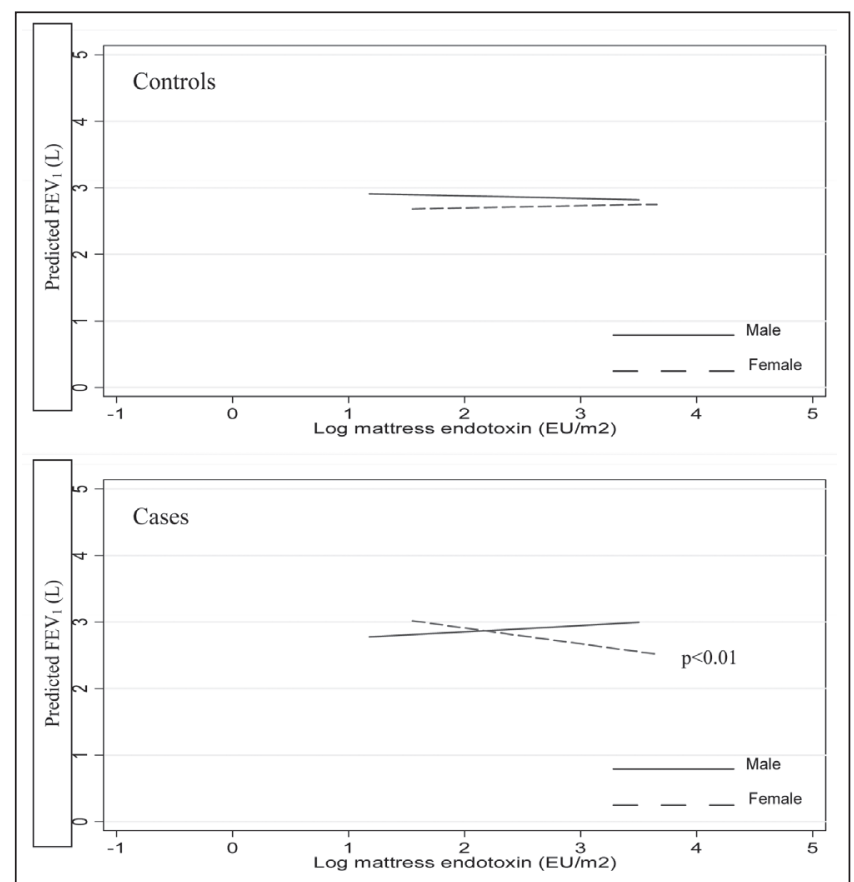

Figure 3) Association between log mattress endotoxin load (EU/m2) and forced expiratory volume in $1 \mathrm{~s}\left(\mathrm{FEV}_{1}\right)$ according to case-control status and sex. Associations are based on models adjusted for age group, sex, casecontrol status, height, season of testing, tobacco smoke exposure, mattress endotoxin load, sex*case-control status, case-control status*mattress endotoxin load, sex*mattress endotoxin load, and case-control status*sex*mattress endotoxin load

Because some medications can influence the results of lung function testing, the use of such medication in our population was assessed. In the present study, $14.9 \%$ of participants were currently using inhaled corticosteroids and $7.1 \%$ were currently using beta-agonists. Only $2.9 \%$ had used a breathing medication on the day of testing. Adjusting for medication use did not influence the lung function findings (data not shown).

\section{DISCUSSION}

In the present study, higher domestic endotoxin levels were associated with lower lung function among female children with pre-existing asthma or wheeze. Additionally, our results suggest that tobacco smoke can modify the association between endotoxin and lung function by resulting in lower FVC. Because there are few population-based studies examining the association between endotoxin and lung function, these results are important and expand on previous research that investigated the associations between endotoxin and the presence of asthma or wheeze. While certain studies have reported protective effects between endotoxin and the presence of respiratory disease in children (5), our results demonstrate the complex nature of endotoxin on lung health by showing that among children with asthma or wheeze, endotoxin can be harmful. This has implications for understanding the role of endotoxin in the development of disease, as well as practical implications on possible ways of reducing morbidity in children with asthma or wheeze.

Our findings are in agreement with a previous study (9) in which endotoxin measured from personal monitoring was inversely associated with daily evening $\mathrm{FEV}_{1}$ among a small sample of children with asthma attending a school designed for children with asthma. Children with asthma or wheeze may be more sensitive to the acute proinflammatory effects of endotoxin than those without asthma or wheeze due to the nonspecific airway hyper-responsiveness and airway inflammatory changes underlying asthma. Results from several laboratory and animal studies suggested that subjects predisposed to atopic disease

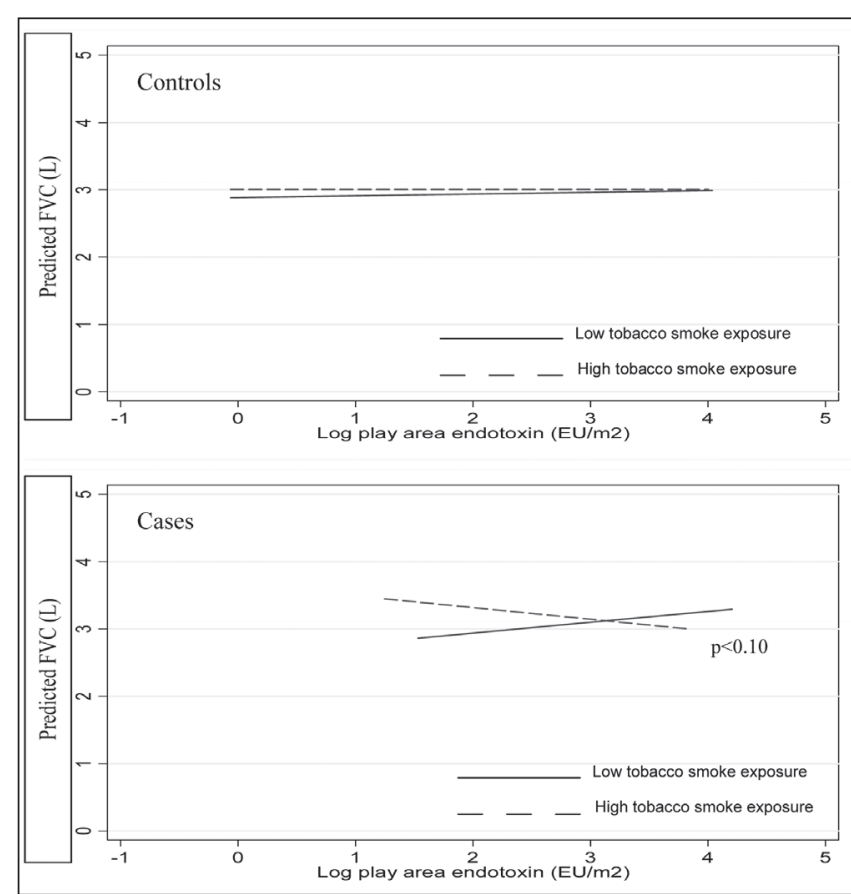

Figure 4) Association between log play area endotoxin load $\left(\mathrm{EU} / \mathrm{m}^{2}\right)$ and forced vital capacity (FVC) according to case-control status and tobacco smoke exposure. The solid line represents subjects with low tobacco smoke exposure and the dotted line represents subjects with high tobacco smoke exposure. Associations are based on models adjusted for case-control status, age group, sex, height, season of testing, play area endotoxin load, tobacco smoke exposure, case-control status*tobacco smoke exposure, case-control status* play area endotoxin load, tobacco smoke exposure* play area endotoxin load, and case-control status*play area endotoxin load*tobacco smoke exposure

experience stronger negative effects of endotoxin, especially in combination with other environmental agents $(10,31)$. The results of our study extend these earlier results by using a human, population-based design in a rural setting.

What is less easy to understand is the difference found between males and females in the associations between lung function and endotoxin. Differences in associations between environmental exposures and various respiratory outcomes have been reported between males and females for asthma symptoms and lung function (29). Also, children with asthma or wheeze in the current study completed a two-week monitoring phase in addition to the testing reported herein. As part of this monitoring, diurnal peak flow variability was calculated, with results showing that tobacco smoke exposure had differential effects on diurnal peak flow variability between boys and girls (32). The current study extends these findings of differential associations of environmental exposures between boys and girls to those with domestic endotoxin exposure, specifically, and its association with $\mathrm{FEV}_{1}$. Female children and adolescents may be more susceptible to environmental effects. A potential explanation for this may be the difference in growth patterns of the airways between boys and girls. Maximum FVC and $\mathrm{FEV}_{1}$ velocity occurs earlier in girls, with different growth patterns near the age of puberty (33). Environmental exposures may alter this lung growth pattern in females, resulting in worse outcomes.

Interaction between tobacco smoke exposure and endotoxin is possible because endotoxin is a component of cigarette smoke (34), tobacco smoke increases the airborne concentration of endotoxin (13) and tobacco smoke exposure has been associated with higher home endotoxin measured from vacuumed home dust (8). Among adults, interactions between tobacco smoke and other exposures have been described in relation to respiratory outcomes in occupational environments including the grain industry (14) - an industry in which work- 
related respiratory symptoms and lower lung function values have also been associated with exposure to occupational endotoxin (35). Furthermore, a synergistic effect between endotoxin and exposure to tobacco smoke has been found in relation to markers of lung inflammation in an animal model (36). We have demonstrated that the interaction between tobacco smoke exposure and household endotoxin can occur in a general population of children. More difficult to interpret, however, is the inconsistency in results between FVC and $\mathrm{FEV}_{1}$ with regard to the role of tobacco smoke exposure. While maternal smoking during pregnancy was not associated with FVC directly and, therefore, not included in the current analysis, it was associated with cotinine levels, suggesting that mothers who smoked during pregnancy continued to smoke or spend time around smokers (data not shown). Because current lung function is a product of both past and current exposures, it may be speculated that this continued exposure from the prenatal period to present, combined with potentially high endotoxin exposure, had an early impact on lung size but not necessarily airway calibre.

The association between lung function and endotoxin exposure described herein was not consistent between the two locations of dust sampling (ie, the play area endotoxin was associated with FVC, while mattress endotoxin was associated with $\mathrm{FEV}_{1}$ ). Previous studies have determined that there are differences in the determinants of endotoxin between different locations sampled in the home $(8,37)$. Also, one study that characterized the types of endotoxin in the home based on the length of fatty acid chain (38) showed that there are qualitative differences between sampling locations. Differences in the health effects of endotoxin can be dependent on the length of fatty acid chain of the endotoxin (39). These observations, along with our findings, may explain some of the inconsistencies in reported associations and suggest that more work is needed to fully understand the implications of using multiple sampling locations in the home.

While results from the present study are consistent with those of adult populations with regard to the potential proinflammatory effects of endotoxin on lung function $(10,11)$, they are in contrast to the results suggesting a protective effect of endotoxin on the presence of asthma in children (5). This is quite plausible considering the difference in outcomes between our study (lung function) and previous studies examining asthma presence. It is possible that the associations with lung function represent the acute effects of endotoxin for children with asthma, while the inverse associations with the presence of asthma and wheeze (5) may reflect long-term effects resulting from more complex immunomodulatory processes with early life exposure, including a shift in the immune response toward a T helper cell 1 response and away from the atopic T helper cell 2 response (40).

Several limitations of the present study should be addressed. While the study incorporated a case-control design, data collection for the

\section{REFERENCES}

1. von Mutius E, Braun-Fahrlander C, Schierl R, et al. Exposure to endotoxin or other bacterial components might protect against the development of atopy. Clin Exp Allergy 2000;30:1230-4.

2. Gereda JE, Leung DYM, Liu AH. Levels of environmental endotoxin and prevalence of atopic disease. JAMA 2000;284:1652-3.

3. Reed CE, Milton D. Endotoxin-stimulated innate immunity: A contributing factor for asthma. Curr Rev Allergy Clin Immunol 2001;108:157-66.

4. Lapa e Silva JR, Possebon da Silva MD, Lefort J, Vargaftig BB. Endotoxins, asthma, and allergic immune responses. Toxicology 2000;152:31-5.

5. Braun-Fahrlander C, Riedler J, Herz U, et al. Environmental exposure to endotoxin and its relation to asthma in school-age children. N Engl J Med 2002;347:869-77.

6. Tavernier GOG, Fletcher GD, Francis HC, et al. Endotoxin exposure in asthmatic children and matched healthy controls: Results of IPEADAM study. Indoor Air 2005;15 (Suppl 10):25-32.

7. Thorne PS, Kulhankova K, Yin M, Cohn R, Arbes SJ Jr, Zeldin DC. Endotoxin exposure is a risk factor for asthma: The National Survey of Endotoxin in United States housing. Am J Respir Crit Care Med 2005;172:1371-7. analysis occurred at one point in time and used prevalent cases, making it vulnerable to cross-sectional limitations including a lack of temporal assessment or misclassification due to recall bias. Due to practical considerations, this is typical of asthma case-control studies $(6,8)$. In contrast, strengths of our study include the use of objective measures of exposure assessment for the primary exposures (endotoxin and tobacco smoke) and the use of objective lung function measurements. Research technicians who conducted the objective measurements and administered standardized questionnaires were carefully trained and supervised.

\section{SUMMARY}

There was a suggestion of an inverse association between endotoxin and lung function; however, this association was only evident among cases, and was modified by sex and tobacco smoke exposure, suggesting that if asthma or wheeze is present, negative health consequences can occur if children are exposed to endotoxin. This is important because it helps provide a clearer understanding of the role of endotoxin in the development and morbidity of asthma and wheeze. Also, the present study was one of the first to report on the association between endotoxin and lung function using a population-based sample of children, and results in several research and practical implications. Future research into the interaction effects may help explain the mechanisms by which endotoxin affects the development of lung health. It may also be important for children with asthma or wheeze to avoid higher endotoxin exposure, especially if the children are female or exposed to tobacco smoke.

ACKNOWLEDGEMENTS: The authors acknowledge Vernice Engele Nazmun Nahar, Thelma Schedlosky, Jeremy Thiessen and Nicole White for their work on data collection and/or data entry. They also acknowledge Lalita Bhradwaj, Justin Gawaziuk, Shelley Kirychuk, Carla Reiman, David Schneberger, Phil Willson, Volker Gerdts and Sylvia van den Hurk's for help in the laboratory analysis. The authors thank Reverend Joanne Beacon and the St Andrew's Anglican Church in Humboldt, Saskatchewan, for the provision of our testing location. Most importantly, we acknowledge and thank all of the children, parents, teachers and schools that participated in this study. This study was funded by the Canadian Institutes of Health Research (CIHR) MOP-57907. Personal funding was received from: the CIHR Strategic Training Initiative in Health Research: Public Health and the Agricultural Rural Ecosystem; the Alberta Heritage Foundation for Medical Research; and the Canadian Centre for Health and Safety in Agriculture in Saskatoon, Saskatchewan, Canada.

FUNDING: Canadian Institutes of Health Research (Grant no: MOP57907).

8. Rennie DC, Lawson JA, Kirychuk S, et al. Assessment of endotoxin levels in the home and current asthma and wheeze in school-age children. Indoor Air 2008;18:447-53.

9. Rabinovitch N, Liu AH, Zhang L, et al. Importance of the personal endotoxin cloud in school-age children with asthma. J Allergy Clin Immunol 2005;116:1053-7.

10. Michel O, Kips J, Duchateau J, et al. Severity of asthma is related to endotoxin in house dust. Am J Respir Crit Care Med 1996;154:1641-46.

11. Michel O, Ginanni R, Duchateau J, Vertongen F, Le Bon B, Sergysels R. Domestic endotoxin exposure and clinical severity of asthma. Clin Exp Allergy 1991;21:441-8.

12. Cook DG, Strachan DP, Carey I. Parental smoking and spirometric indices in children. Thorax 1998;53:884-93.

13. Larsson L, Szponar B, Pehrson C. Tobacco smoking increases dramatically air concentrations of endotoxin. Indoor Air 2004:14:421-4.

14. Cotton DJ, Graham BL, Li K-YR, Froh F, Barnett GD, Dosman JA. Effects of smoking and occupational exposure on peripheral airway function in young cereal grain workers. Am Rev Resp Dis. $1982 ; 126: 660-5$ 
15. The International Study of Asthma and Allergies in Childhood (ISAAC) Steering Committee. Worldwide Variations in the Prevalence of Asthma Symptoms: The International Study of Asthma and Allergies in Childhood (ISAAC). Eur Respir J 1998;12:315-35.

16. Ferris B Jr. Epidemiology Standardization Project. Am Rev Respir Dis 1978;118:36-47.

17. NIEHS. US Department of Housing and Urban Development National Institute of Environmental Health Sciences National Survey of Lead Hazards and Allergens in Housing - Resident Questionnaire. 2004 <www.niehs.nih.gov/research/clinical/join/ studies/riskassess/nslah.cfm> (Accessed on October 31, 2011).

18. Chen Y, Rennie D, Dosman J. Influence of environmental tobacco smoke on asthma in nonallergic and allergic children. Epidemiology 1996;7:536-9.

19. Rennie DC, Lawson JA, Cockcroft DW, Senthilselvan A, McDuffie HH. Differences in respiratory symptoms and pulmonary function in children in 2 Saskatchewan communities. Ann Allergy Asthma Immunol 2004;92:52-9.

20. Weiland SK, Bjorksten B, Brunekreef B, et al. Phase II of the International Study of Asthma and Allergies in Childhood (ISAAC II): Rationale and methods. Eur Resp J 2004;24:406-12.

21. Chan-Yeung M, Manfreda J, Dimich-Ward H, et al. Mite and cat allergen levels in homes and severity of asthma. Am J Respir Crit Care Med 1995;152:1805-11.

22. Gereda JE, Leung DYM, Thatayatikom A, et al. Relation between house-dust endotoxin exposure, type $1 \mathrm{~T}$-cell development, and allergen sensitization in infants at high risk of asthma. Lancet 2000;355:1680-3.

23. Jarvis MJ, Russell MAH, Feyerabend C, et al. Passive exposure to tobacco smoke: Saliva cotinine concentrations in a representative population sample of non-smoking schoolchildren. BMJ 1985;291:927-9.

24. American Thoracic Society. Standardization of spirometry: 1994 update. Am J Respir Crit Care Med 1995;152:1107-36.

25. Sensormedics. Operating Instructions. Predicted Equations and References. Yorba Linda: Sensormedics, 1992.

26. Michel O, Duchateau J, Sergysels R. Effect of inhaled endotoxin on broncial reactivity in asthmatic and normal subjects. J Appl Physiol 1989;66:1059-64.

27. Lawson JA, Rennie DC, Senthilselvan A, Cockcroft DW, $\mathrm{McDuffie} \mathrm{HH}$. Regional variations in risk factors for asthma in school children. Can Respir J 2005;12:321-6.
28. Lawson JA, Rennie DC, Senthilselvan A, McDuffie HH, Cockcroft D. Occurrence of new-onset wheeze in a 3-year follow-up study of schoolchildren. Ann Allergy Asthma Immunol 2007;99:502-8.

29. Holmen TL, Barrett-Connor E, Clausen J, Langhammer A, Holmen J, Bjermer L. Gender differences in the impact of adolescent smoking on lung function and respiratory symptoms. The Nord-Trondelag Health Study, Norway, 1995-1997. Respir Med 2002;96:796-804.

30. Tollefsen E, Bjermer L, Langhammer A, Johnsen R, Holmen TL. Adolescent respiratory symptoms - girls are at risk: The Young-HUNT study, Norway. Respir Med 2006;100:471-6.

31. Tulic MK, Wale JL, Holt PG, Sly PD. Modification of the inflammatory response to allergen challenge after exposure to bacterial lipopolysaccharide. Am J Repir Cell Mol Biol 2000;22:604-12.

32. Lawson JA, Dosman JA, Rennie DC, Beach J, Newman SC, Senthilselvan A. Relationship of endotoxin and tobacco smoke exposure to wheeze and diurnal peak expiratory flow variability in children and adolescents. Respirology 2011;16:332-9.

33. Wang X, Dockery DW, Wypij D, et al. Pulmonary function growth velocity in children 6 to 18 years. Am Rev Respir Dis 1993;148:1502-8.

34. Hasday JD, Bascom R, Costa JJ, Fitzgerald T, Dubin W. Bacterial endotoxin is an active component of cigarette smoke. Chest 1999;115:829-35.

35. Schwartz DA, Thorne PS, Yagla SJ, et al. The role of endotoxin in grain dust-induced lung disease. Am J Respir Crit Care Med 1995;152:603-8.

36. Kulkarni GS, Nadkarni PP, Cerreta JM, Ma S, Cantor JO. Short-term cigarette exposure potentiates endotoxin-induced pulmonary inflammation. Exp Lung Res 2007;33:1-13.

37. Waser M, von Mutius E, Maisch S, et al. Determinants of endotoxin levels in living environments of farmers' children and their peers from rural areas. Clin Exp Allergy 2004;34:389-97.

38. Park J-H, Szponar B, Larsson L, Gold DR, Milton D. Characterization of lipopolysaccharides present in settled house dust. Appl Environ Microbiol 2004;70:262-7.

39. Zhao Z, Sebastian A, Larsson L, Wang Z, Zhang Z, Norback D. Asthmatic symptoms among pupils in relation to microbial dust exposure in schools in Taiyuan, China. Pediatr Allergy Immunol 2008;19:455-65.

40. Liu AH. Endotoxin exposure in allergy and asthma: Reconciling a paradox. J Allergy Clin Immunol 2002;109:379-92. 


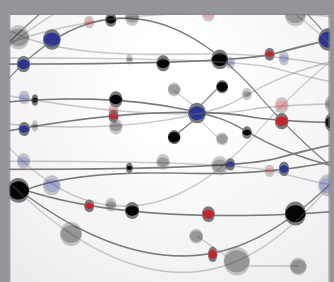

The Scientific World Journal
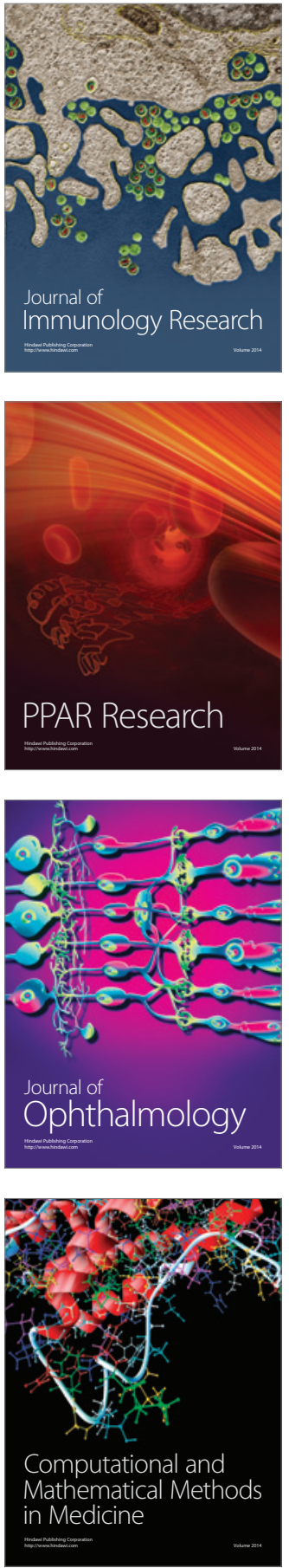

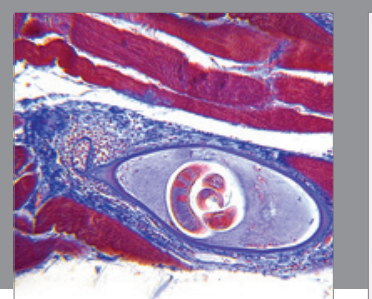

Gastroenterology Research and Practice

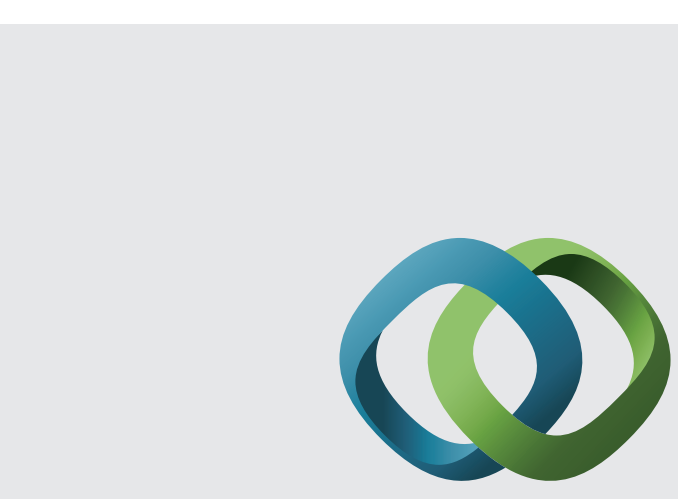

\section{Hindawi}

Submit your manuscripts at

http://www.hindawi.com
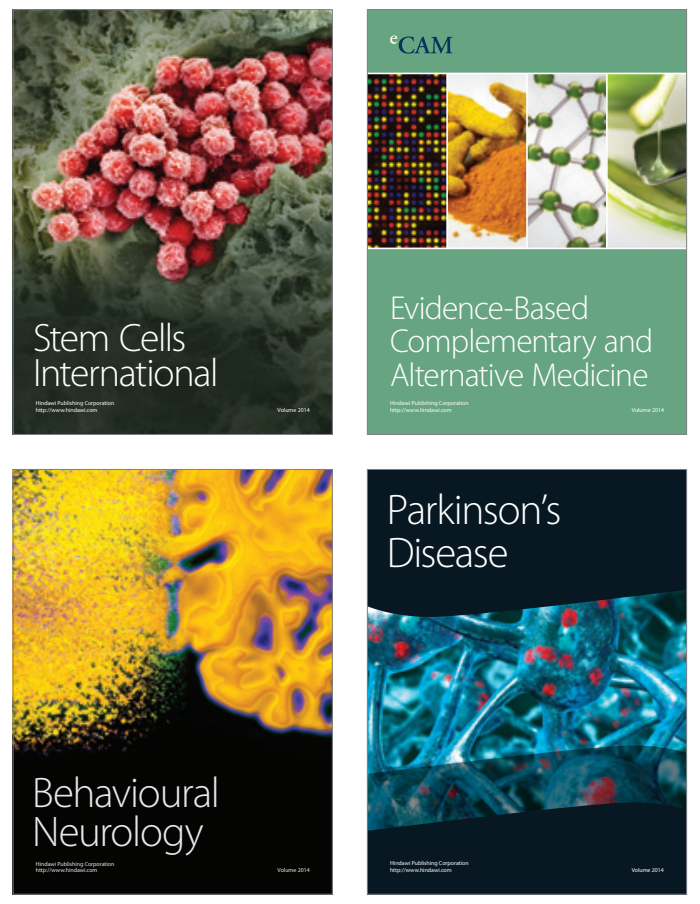
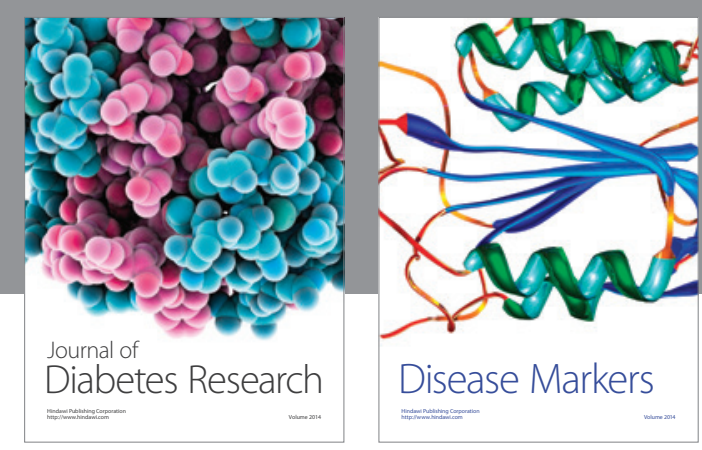

Disease Markers
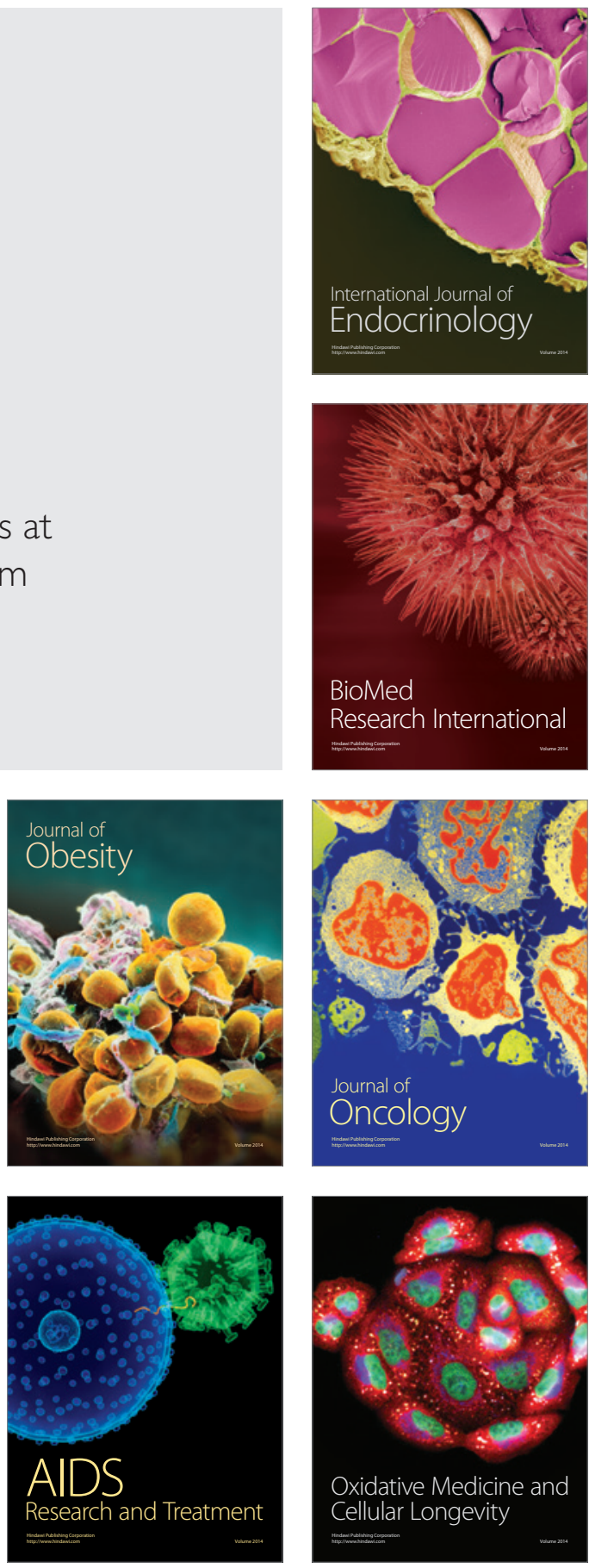